\title{
The soil-physical basis of the improvement of clay cover-soils
}

\author{
G. P. WIND and A. P. HIDDING \\ Institute for Land and Water Management Research, Wageningen, The Netherlands
}

\begin{abstract}
Summary
Clay cover-soils (a shallow clay layer upon a sandy subsoil) are very susceptible to drought. The cause of this is, that no roots penetrate into the sand. The crop can therefore only use the moisture of the shallow clay cover and some moisture that can flow capillarily out of the sand to the root zone. There are two possible methods for improvement of these soils: sub-irrigation in spring with saline wate and deep-plowing by which clay and sand are mixed.

The amounts of available moisture are computed for different depths of the spring groundwater table (TABLE 4). The amounts in the root zone with the aid of pF-curves and those in the capillary zone with a formula for the relation between capillary conductivity and pF. From potential evapotranspiration- and rainfall data, the mean actual evapotranspiration in the growing season is calculated (TABLE 6) for different amounts of available moisture. Under the assumption that there is a rectilinear relation between yield and actual evapotranspiration, the agricultural production capacities were calculated (TABLE 7).

The conclusions are that a groundwater table of $100 \mathrm{~cm}$ below soil surface gives a sufficient moisture supply for deep-plowed cover-soils and that cover-soils that are not deep-plowed will not reach a high productivity.
\end{abstract}

\section{Introduction}

In the Netherlands there are some 15.000 ha of clay cover-soils. These consist of a cover of silty to heavy clay overlying a medium-coarse sand. Taking as definition of clay particles those particles that are $<2 \mu$ in diameter, the clay content of the cover varies from 10 to $40 \%$ with an average of $20 \%$. The sand contains less than $4 \%$ clay and no organic matter, the granular composition is approximately: $8 \%$ from 75 to $105 \mu, 56 \%$ from 105 to $150 \mu$ and $31 \%$ from 150 to $210 \mu$ (KuIPERs, 1960).

Between the clay cover and the marine sandy subsoil, only a thin transition layer is present. The cover is seldom thinner than $20 \mathrm{~cm}$. If it is thicker than $70 \mathrm{~cm}$ we no longer call it a cover-soil. In most cases the cover is some $30 \mathrm{~cm}$ thick.

The crops grown on these soils suffer from drought nearly every spring and often in summer. The yields are much lower than those obtained from deeper soils. VAN DEN BERG (1955) found that roots do not penetrate into the sandy subsoil. HidDiNG and VAN DEN Berg (1960) showed that this is caused by the high density of the underlying sand.

Due to the thin rooted layer, plants on these profiles have only 60 to $80 \mathrm{~mm}$ available moisture. When the groundwater table is high, the plants can profit from capil-

Received for publication 22nd September, 1961.

Neth. J. agric. Sci., Vol. 9 (1961) No. 4 (November) 
lary rise of moisture from below the root zone. Normally, however, these soils have rather deep groundwater tables. The majority of clay cover-soils are situated in the province of Zeeland, where the groundwater and the water in the canals is saline. Fresh water for irrigation purposes is not available.

Two possible improvements can be made to these soils : sub-irrigation with saline water, and a mixing of clay and sand by means of deep-plowing. In this article the advantages of these improvements will be calculated in terms of available moisture. In a later article the agricultural results of the improvements will be discussed.

\section{Calculation of available moisture}

In calculating the total amount of available moisture in the profiles, difference is made between the moisture which is present in the root zone and the moisture which must first be transported by capillary action from below the root zone. The latter we call sub-root zone moisture. In the rooted layer, complete depletion of soil moisture to the permanent wilting percentage is possible. In the capillary zone, depletion is only possible to a certain extent, depending on the capillary conductivity of the sand.

We assume that in dry periods the loss of water by drainage can be neglected and that no supply of groundwater takes place during the growing season except from rain.

\section{Available moisture in the root zone}

In the root zone we can calculate the amount of available moisture with the aid of the pF-curves of FIG. 1 for different depths of the groundwater table in spring. The clay-sand mixture of which the pF-curve was determined, was very thoroughly mixed in the laboratory with an equal part of clay with $20 \%$ particles $<2 \mu$. It is to be expected that a thorough mixing will give a better imitation of a soil with $10 \%$ particles $<2 \mu$ than rough mixing will do. It appeared that the pF-curves of mixtures of various fineness did not differ to a great extent (see TABLE 1).

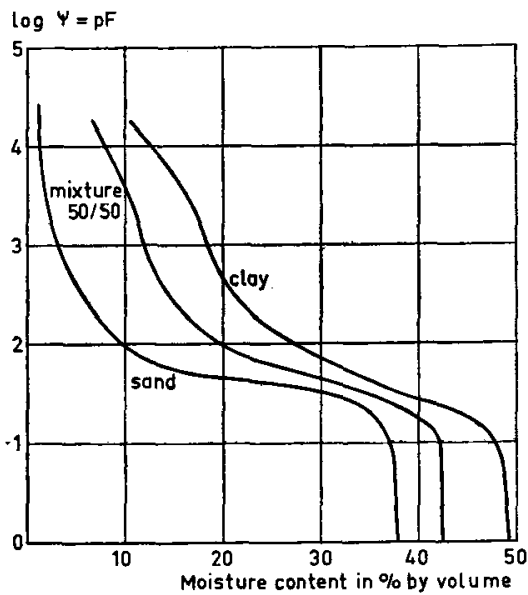

282
FIG. 1. Moisture characteristic for the clay cover, the sandy subsoil and the 50/ 50 mixture 
TABLE 1. Moisture percentage by volume for some suction values of clay-sand mixtures with different fineness of the clay

\begin{tabular}{|c|c|c|c|c|c|}
\hline \multirow{2}{*}{$\begin{array}{c}\text { Clay-sand mixture } 50 / 50 \text { made from } \\
\text { sand and: }\end{array}$} & \multicolumn{5}{|c|}{$\mathrm{pF}$} \\
\hline & 1,0 & 2,0 & 2,7 & 3,4 & 4,2 \\
\hline grinded clay & 42,2 & 19,6 & 12,9 & 10,9 & 6,9 \\
\hline aggregates $<0,8 \mathrm{~cm}$ & 39,6 & 19,5 & 13,4 & 10,3 & 6,8 \\
\hline clods $0,8-2,0 \mathrm{~cm} \ldots$ & 38,6 & 20,3 & 14,4 & 10,0 & 6,4 \\
\hline
\end{tabular}

This means that mixing does not create a new soil with new physical properties; a mixture of two soils does remain. The properties of this mixture are the sum or the mean of those of the component parts.

TABLE 2 gives the amount of available moisture in the root zone for the original cover soil of $30 \mathrm{~cm}$ depth and for the $60 \mathrm{~cm}$ deep mixed soil.

TABLE 2. Available moisture in $\mathrm{mm}$ in the root zone before and after deep plowing

\begin{tabular}{ccccc}
$\begin{array}{c}\text { Depth of water } \\
\text { table in cm }\end{array}$ & $\begin{array}{c}\text { Original cover } \\
\text { (moisture in } \\
30 \mathrm{~cm} \text { clay) }\end{array}$ & $\begin{array}{c}\text { New cover } \\
\text { (moisture in } \\
60 \mathrm{~cm} \text { mixture) }\end{array}$ & $\begin{array}{c}\text { Original profile } \\
\text { (moisture in } 30 \mathrm{~cm} \\
\text { clay }+30 \mathrm{~cm} \text { sand) }\end{array}$ & $\begin{array}{c}\text { Moisture gain } \\
\text { by deep-plowing }\end{array}$ \\
$(1)$ & $(2)$ & $(3)$ & $(4)$ & $(5)$ \\
30 & 103 & 208 & 211 & 105 \\
60 & 72 & 169 & 175 & 97 \\
90 & 60 & 115 & 132 & 35 \\
120 & 51 & 83 & 88 & 25 \\
150 & 44 & 69 & 69 & 22 \\
180 & 40 & 62 & 61 & 32 \\
\hline
\end{tabular}

The $3 \mathrm{rd}$ column gives the amount of "available" moisture in the original soil to a depth of $60 \mathrm{~cm}$. This moisture is not really available, for in the lower $30 \mathrm{~cm}$ a large potential gradient must exist if capillary flow will keep up with evaporation. The difference between column 3 and 4 is zero for dry circumstances and negative in moist and wet conditions. So the moisture gain by deep-plowing is at the most equal to the amount originally present in the plowed sand. From column 5 it can be seen that the moisture increase through deep-plowing is the higher, the smaller the depth of the groundwater table.

Although TABLE 2 does not include the amounts of moisture available via the capillary zone, it is already clear that a large increase of moisture can only be expected when high water tables occur.

\section{Capillary conductivity of the marine sand}

To calculate the amount of moisture the plant can use from below the rooted zone, we need to know the flow velocities and the suction gradients that exist in the sandy subsoil.

Since good results were obtained measuring flow potentials by nylon units in a heavy clay soil (WIND, 1955), the same technique was applied here.

Undisturbed samples of the marine sand below the rooting zone, were taken in 
cylinders with a diameter of $10 \mathrm{~cm}$ and $40 \mathrm{~cm}$ length. Nylon units were brought-in through the wall of the cylinders with depth intervals of $5 \mathrm{~cm}$. After the cylinders had lost nearly all moisture, they were wetted with a saturated gypsum solution. They were allowed to drain, protected against evaporation, until the weight of them, and the resistance of the nylon units remained constant. Then evaporation was started. Every day the cylinders were weighed and the resistances of the nylon units were read.

The flow velocities and the gradients in capiliary potential during the period of the experiment were calculated for different depths in the cylinders. From these data the capillary conductivity could be obtained. In FIG. 2 the capillary conductivity data are plotted against the moisture potentials belonging to them. As one could expect of such a soil, sand without any clay or organic matter, the gradient is rather steep :

$$
\log \lambda=-3 \log \psi+4,95 \quad 1,6<\log \psi<3,0
$$

In equation (1) $\lambda$ is the capillary conductivity in $\mathrm{mm}$ per day and $\psi$ the capillary potential in $\mathrm{g} / \mathrm{cm}^{2}$. This equation only holds from $\log \psi=1,6$ to $\log \psi=3,0$. Weather conditions were not investigated in the cylinders. Nevertheless it is known, that the saturated permeability equals about $3 \mathrm{~m} /$ day. So for $\log \psi=0, \log \lambda$ is appr. 3,5. Therefore it looks reasonable that we may apply equation (1) for much lower values of the capillary potential than $\log \psi=1,6$. In the application it makes no dif-

FIG. 2. Relation of capillary conductivity $(\lambda)$ and moisture potential $(\psi)$ of the sandy subsoil

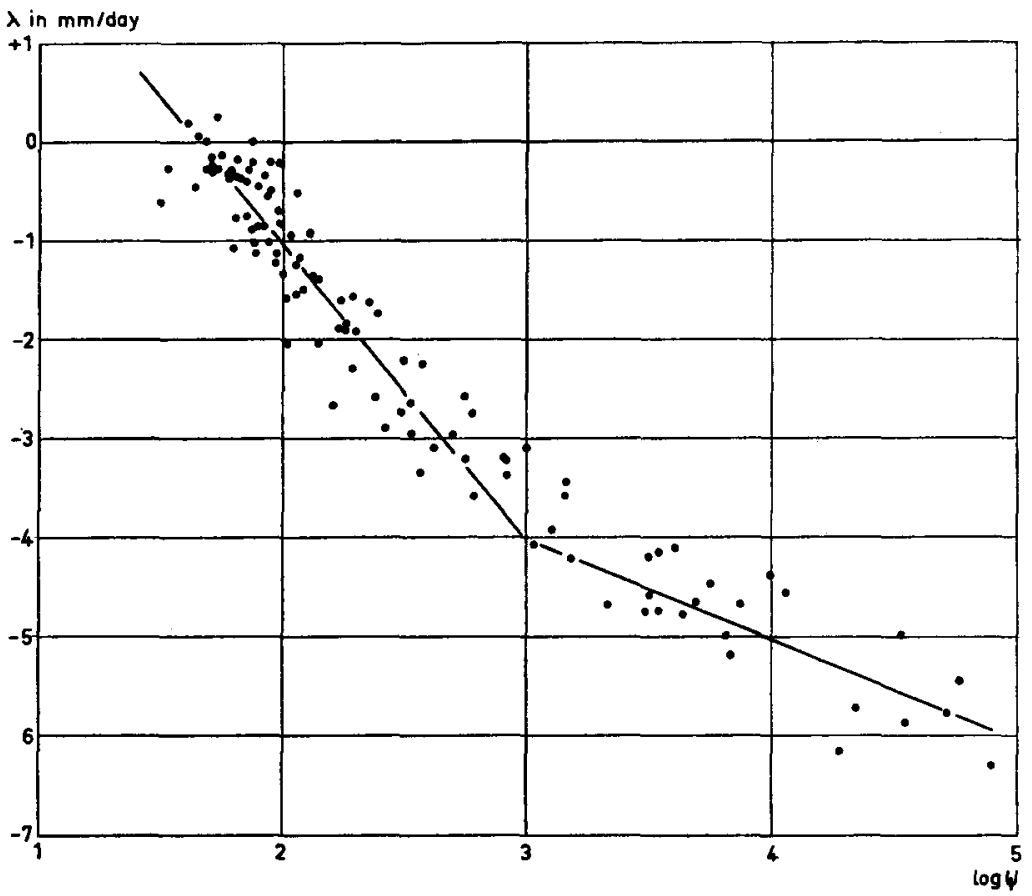


ference if for $\log \psi=0$, the capillary conductivity is $3 \mathrm{~m} /$ day or still higher. The introduction of a factor $b$ as meant by GARDNER (1958) is therefore not necessary here and we operate with eq. (1) from $\log \psi=0$ to $\log \psi=3,0$.

In the dry part (above $\mathrm{pF}=3$ ) the inclination of the curve is lesser, it follows the relation:

$$
\log \lambda=-\log \psi-0,85 \quad \log \psi>3,0
$$

The values of $\lambda$, due to formula (2) are so small, that for flow velocities $\geqslant 0,5 \mathrm{~mm}$ / day, the $\mathrm{pF}$ increases from 3 to 4 within $1 \mathrm{~cm}$.

\section{Calculation of available moisture below the root zone}

With the knowledge of the capillary conductivity we can calculate potential profiles for steady state flow.

From

$$
\begin{gathered}
\lambda=\mathrm{b} \psi^{-\mathrm{a}} \\
\mathrm{V}=\lambda\left(\frac{\mathrm{d} \psi}{\mathrm{db}}-1\right)
\end{gathered}
$$

and

(where $\mathrm{V}$ is the flow velocity in $\mathrm{mm} /$ day, $\mathrm{h}$ the height above the groundwater table and $\mathrm{a}$ and $\mathrm{b}$ constants)

we find :

$$
\mathrm{dh}=\frac{\mathrm{d} \psi}{\frac{\mathrm{V}}{\mathrm{b}} \psi^{\mathrm{a}}+1}
$$

For $a=3$ and $\log b=4,95$ the solution is

$$
\mathbf{h}=\mathrm{c}\left\lceil\frac{1}{6} \ln \frac{(\mathrm{c}+\psi)^{2}}{\mathrm{c}^{2}-\mathrm{c} \psi+\psi^{2}}+\frac{1}{\sqrt{3}} \operatorname{tg}^{-1} \frac{2 \psi-\mathrm{c}}{\mathrm{c} \sqrt{3}}+0,303\right\rceil
$$

In which $\quad \mathrm{c}^{3}=\frac{0,9 \times 10^{5}}{\mathrm{~V}}$

In FIG. 3 the potential profiles ( $h, \log \psi$ diagrams) are given for different flow velocities. It is notable that the curves are nearly horizontal in the range 3 to 4 of $\log \psi$. This is a characteristic difference with potential profiles of clay soils, where there are much smaller potential gradients in this range.

In the clay cover-soils a controlled groundwater table is out of the question. For any decrease of the moisture content in the capillary zone a drawdown of the groundwater table is required. So the existence of a steady state flow is impossible. The quantity of available moisture must therefore be computed with formulas for nonsteady state flow. As Wesseling (1957) proposed, we use here an approximate, graphical solution of the problem. With this method we can find an approximation for the maximum amounts of moisture which can be extracted from below the root zone in a given number of days.

One can draw FIG. 3 in such a manner that all curves come together in the lower end of the root zone where we assume that $\mathrm{pF}=4$. This has been done in FIG. 4. The lower end of the root zone is put at a depth $(h)$ zero in the diagram; $h=20$ 


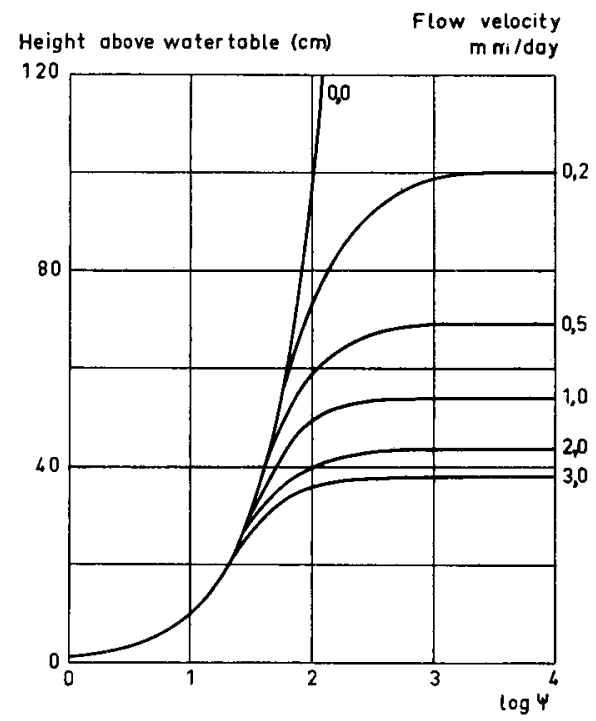

FIg. 3. Potential profiles for different flow velocities in the sandy subsoil

is therefore $20 \mathrm{~cm}$ below the root zone. Instead of $\mathrm{pF}$ against depth, in FIG. 4 the moisture content (V) against depth is shown, the so-called moisture profile. The moisture above a certain curve, e.g. the curve for $\mathrm{V}=1$ can be extracted with flow velocities $>1$. For all the moisture below this curve, flow velocities larger than 1 are impossible. All moisture below the curve $\mathrm{V}=2$ cannot be extracted with flow velocities $>2$. So the maximum flow velocity with which the moisture between the

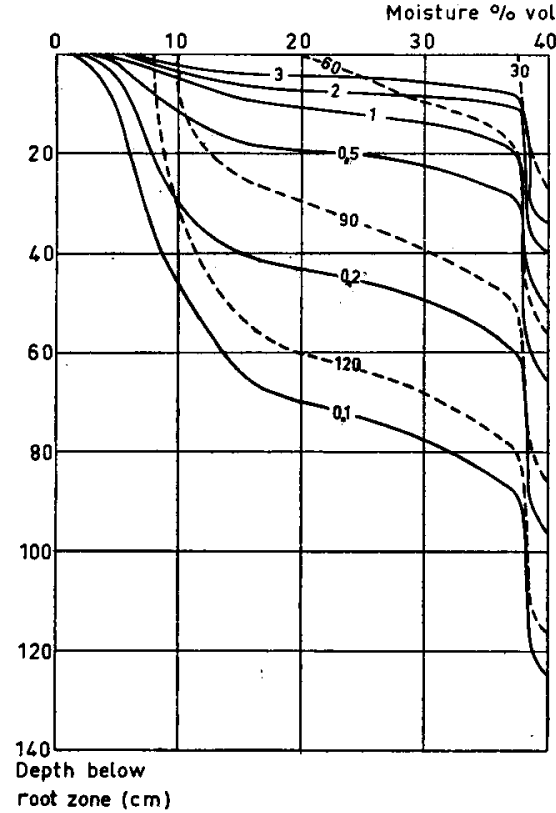

FIG. 4. Moisture profiles in the sandy subsoil for different flow velocities (full lines) and for zero flow with different depths of the groundwater table (broken lines) 
curves $\mathrm{V}=1$ and $\mathrm{V}=2$ can be extracted lies between 1 and $2 \mathrm{~mm} /$ day. Lower velocities are possible and they will occur mostly, but the maximum velocity will be appr. $1,5 \mathrm{~mm} /$ day as a mean for this moisture. In the same way, for moisture between the curves $\mathrm{V}=1$ and $\mathrm{V}=0,5$, the maximum velocity will be appr. $0,75 \mathrm{~mm} /$ day.

The broken lines give the amounts of moisture present at field capacity $(\psi=\mathrm{h}$ ) for different depths of the water table. By measuring the surface between the curves for $\mathrm{V}=1$ and $\mathrm{V}=0,5$ and to the left of the field capacity curve of $90 \mathrm{~cm}$ we find the amount of moisture which is present in the profile with a spring water table of $90 \mathrm{~cm}$ below soil surface and which can be extracted with a maximum velocity of appr. $0,75 \mathrm{~mm} /$ day. To the right of the broken line there is no water, so it cannot be extracted.

The amounts of moisture with their maximum mean extraction velocities can be found in TABLE 3 for different depths of the groundwater. Though it is possible to compute the curves for $\mathrm{V}=4$ and more, these values are for the Netherlands of little importance. Only seldom the flow velocity in the limit horizon between root- and capillary zone exceeds $3 \mathrm{~mm} /$ day in our climate.

In dividing the amounts $m$ by the extraction velocity $V$, one finds the time $t$ during which the extraction takes place with the given velocity.

For applying the data of TABLE 3 we need the amount of moisture which becomes available in a certain period, e.g. during a dry period of a certain length or during the whole growing period. A linear interpolation between the figures of TABLE 3 is not allowed because the first millimeter in a group will be extracted with greater velocity than the last. The data are therefore brought in an additional curve, FIG. 5 . From this graph it is possible to read the maximum amounts of moisture which can be extracted in a given number of days. One can see that the biggest difference

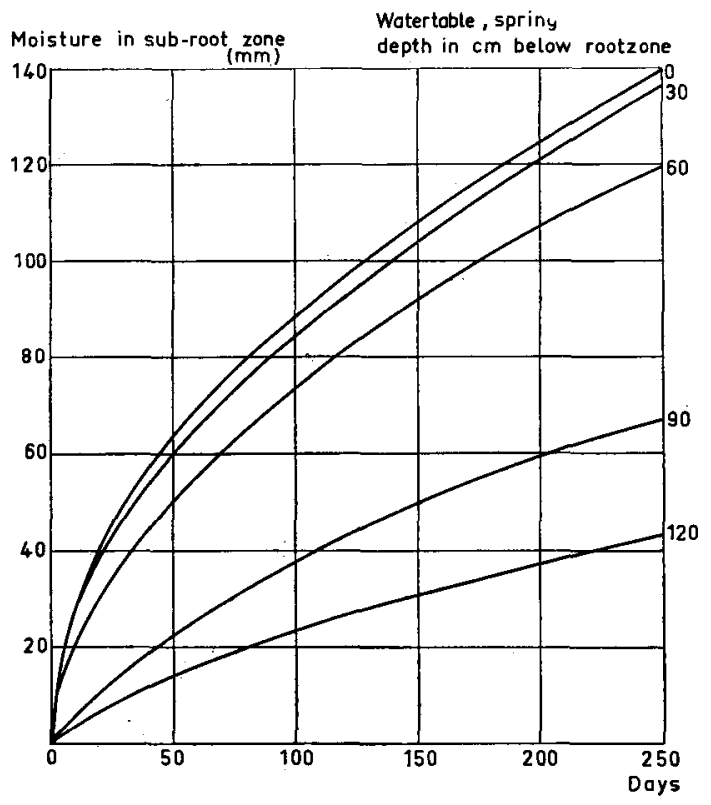

FIG. 5. Maximum amounts of moisture that can be extracted in a certain period from below the root zone, for different groundwater depths 
exists between the addition curves for 60 and $90 \mathrm{~cm}$ depth of groundwater below the rooting zone.

TABLE 3. Amounts of moisture $(\mathrm{m})$ which can be extracted with mean maximum velocity (V) during a certain time $\mathrm{t}=\mathrm{m} / \mathrm{V}$

\begin{tabular}{|c|c|c|c|c|c|c|c|c|c|c|c|c|}
\hline \multirow{2}{*}{$\begin{array}{l}\text { Depth of groundwater } \\
\text { table in spring, in } \mathrm{cm} \\
\text { below root zone }\end{array}$} & \multicolumn{2}{|c|}{$\mathrm{V}=3 \mathrm{~mm} /$ day } & \multicolumn{2}{|c|}{$\mathbf{V}=2,5$} & \multicolumn{2}{|c|}{$V=1,5$} & \multicolumn{2}{|c|}{$V=0,75$} & \multicolumn{2}{|c|}{$V=0,35$} & \multicolumn{2}{|c|}{$V=0,15$} \\
\hline & $\underset{(\mathrm{mm})}{\mathrm{m}}$ & $\begin{array}{c}\mathrm{t} \\
\text { (days) }\end{array}$ & $\mathrm{m}$ & $\mathrm{t}$ & $\mathrm{m}$ & $t$ & $\mathrm{~m}$ & $t$ & $\mathrm{~m}$ & $\mathrm{t}$ & $\mathrm{m}$ & $t$ \\
\hline 0 & 19 & 6 & 7 & 3 & 14 & 9 & 28 & 38 & 80 & 228 & & \\
\hline 30 & 15 & 5 & 6 & 3 & 14 & 9 & 28 & 38 & 80 & 228 & & \\
\hline 60 & 5 & 2 & 4 & 1 & 9 & 6 & 25 & 33 & 80 & 228 & & \\
\hline 90 & 0 & 0 & 0 & 0 & 1 & 1 & 2 & 3 & 42 & 119 & & \\
\hline 120 & 0 & 0 & 0 & 0 & 0 & 0 & 1 & 1 & 3 & 9 & 38 & 225 \\
\hline
\end{tabular}

\section{Total maximal available moisture in the soil}

The total amount of moisture the crop can use, is the sum of the moisture in the root zone plus the amounts of moisture which can be supplied from the capillary zone. So we add the data of TABLE 2 and FIG. 5. In the first the depth of the groundwater table is given in $\mathrm{cm}$ below the soil surface, in the latter, however, in $\mathrm{cm}$ below the lower boundary of the rooting zone. The rooting zone in the given example is $30 \mathrm{~cm}$ deep for the original cover-soil and $60 \mathrm{~cm}$ for the by deepplowing improved soil. So a groundwater table of $90 \mathrm{~cm}$ in table 2 agrees with a water table of $60 \mathrm{~cm}$ in FIG. 5 for the original and of $30 \mathrm{~cm}$ for the plowed soil. In TABLE 4 the results of the calculation are given for a period of 100 days, approximately the length of the dry period in the growing season of grains, peas and flax.

TABLE 4. Maximum amounts of available moisture in 100 days

\begin{tabular}{|c|c|c|c|c|c|c|c|c|c|}
\hline \multirow{2}{*}{$\begin{array}{l}\text { Groundwater } \\
\text { table in } \mathrm{cm} \\
\text { below surface }\end{array}$} & \multicolumn{3}{|c|}{ Before plowing } & \multicolumn{3}{|c|}{ After deep plowing } & \multicolumn{3}{|c|}{ Benefit by plowing } \\
\hline & $\begin{array}{l}\text { root } \\
\text { zone }\end{array}$ & $\begin{array}{l}\text { sub-root } \\
\text { zone }\end{array}$ & total & $\begin{array}{l}\text { root } \\
\text { zone }\end{array}$ & $\begin{array}{l}\text { sub-root } \\
\text { zone }\end{array}$ & total & $\begin{array}{l}\text { root } \\
\text { zone }\end{array}$ & $\begin{array}{l}\text { sub-root } \\
\text { zone }\end{array}$ & total \\
\hline 30 & 103 & 87 & 190 & 208 & 87 & 295 & 105 & 0 & 105 \\
\hline 60 & 71 & 84 & 156 & 169 & 87 & 256 & 97 & 3 & 100 \\
\hline 90 & 60 & 74 & 134 & 115 & 84 & 199 & 55 & 10 & 65 \\
\hline 120 & 51 & 38 & 89 & 83 & 74 & 157 & 32 & 36 & 68 \\
\hline 150 & 44 & 23 & 67 & 69 & 38 & 107 & 25 & 15 & 40 \\
\hline 180 & 40 & 14 & 54 & 62 & 23 & 85 & 22 & 9 & 31 \\
\hline
\end{tabular}

\section{Moisture requirement of the crop}

At present only little is known about the moisture use of arable land. For grassland Penman (1948) gave a good approxixmation, but there is some evidence that the evapotranspiration of other crops is not proportional to that of grassland (DE WIT, 1958; WIND, 1954). In calculating the potential evapotransporation of arable land we used estimated reduction factors with which the evaporation data $\left(E_{0}\right)$ were multiplied: March 0,6; April 0,7; May 0,8; June 1,0; July 0,5. In March and April summer grains, peas and flax do not cover the soil completely. So to use a low 
factor is reasonable. In May the crops cover the field and are of small ineight. The factor will then be about the same as for grass. In June grains and flax have grown higher, WIND (1954) found very high evapotranspirations in this month. In July many leafs die off, so transpiration is strongly reduced.

For winter wheat the factors in March and April will be somewhat higher. For beets and potatoes they will be lower, even in May; but for July a higher factor is plausible. For these crops there can be a precipitation deficit in August too.

From the approximated evapotranspiration data calculated in the mentioned manner and the rainfall data from 20 years, the precipitation deficits were computed (TABLE 5). Since rainfall data over 1953 have never been published and a continuous period was required, 1952 has been taken as the last year of the period.

TABLE 5. Approximated precipitation deficits from March through July (1932-1952)

\begin{tabular}{|c|c|c|c|}
\hline $120-150 \mathrm{~mm}$ & over & 6 & years \\
\hline $150-180 \mathrm{~mm}$ & & 7 & \\
\hline $180-210 \mathrm{~mm}$ & & 5 & \\
\hline $210-240 \mathrm{~mm}$ & & 2 & , \\
\hline
\end{tabular}

With the aid of those deficits the actual evapotranspiration was calculated for the 20 years. These data were averaged. The mean actual evapotranspiration can be found in TABLE 6.

TABLE 6. Mean actual evapotranspiration from March through July, average of 20 years

\begin{tabular}{cc}
$\begin{array}{c}\text { Available soil moisture } \\
\text { in mm }\end{array}$ & $\begin{array}{c}\text { Mean actual evapotranspiration } \\
\text { in } \mathrm{mm}\end{array}$ \\
60 & \\
90 & 240 \\
120 & 270 \\
150 & 300 \\
180 & 320 \\
210 & 341 \\
240 & 349 \\
\hline
\end{tabular}

Many investigators, e.g. Staple and Lehane (1954) and DE Wit (1958), found that in many cases there is a rectilinear relationship between evapotranspiration and crop yield. It is desirable therefore to influence the circumstances in such a way that a high actual evapotranspiration is possible. It is then an economical question which increase of actual evapotranspiration is still paying. An amount of $180 \mathrm{~mm}$ of available soil moisture is then estimated as being necessary.

\section{Preliminary conclusions}

Regarding the requirement of $180 \mathrm{~mm}$ of available soil moisture in the light of the data of TABLE 4, one can see that in the original profile before deep-plowing, the necessary depth of the groundwater table would be $40 \mathrm{~cm}$. It is known that this is too high for arable crops (VAN HooRN, 1958). In most cases the fields are not totally flat, height differences of about $50 \mathrm{~cm}$ are common. So the soil will 
certainly be too wet in the depressions, if $40 \mathrm{~cm}$ is the mean depth of the groundwater in spring. Generally speaking it will not be possible to give a sufficient water supply with sub-irrigation in spring only.

Deep-plowing will give a complete improvement only with spring watertables higher than $100 \mathrm{~cm}$ below surface. If the watertable is below this depth, complete improvement is possible by a combination of deep-plowing and sub-irrigation to $100 \mathrm{~cm}$ below surface.

By combining TABLE 4 and TABLE 6, we find the relation between the depth of the groundwater table and the mean amounts of moisture which can be consumed under the assumption that the potential evapotranspiration is $350 \mathrm{~mm}$. The relative values for the production of arable crops can be calculated. The former and the latter values are given in TABLE 7 .

TABLE 7. Mean actual evapotranspiration and agricultural production capacity of clay cover-soils in relation to the depth of the spring groundwater table

\begin{tabular}{cccccc}
\hline $\begin{array}{c}\text { Depth of water table } \\
\text { in spring }\end{array}$ & \multicolumn{2}{c}{ Actual evapotranspiration $(\mathrm{mm})$} & & \multicolumn{2}{c}{ Production capacity (max. $=100)$} \\
\cline { 2 - 3 } & not plowed & plowed & & not plowed & plowed \\
30 & 344 & 350 & 350 & 98 & 100 \\
60 & 327 & 347 & 93 & 99 \\
90 & 310 & 328 & 89 & 77 & 94 \\
120 & 269 & 287 & 71 & 82 \\
150 & 247 & 265 & 67 & 76 \\
\hline
\end{tabular}

This table gives a theoretical approximation under the conditions mentioned in this article : clay cover $30 \mathrm{~cm}$, plowing depth $60 \mathrm{~cm}$, moisture characteristics as in FIG. 1 and proportionality between actual evapotranspiration and crop yield. Bearing these conditions in mind we come to the following conclusions.

Sub-irrigation cannot give a complete improvement of the clay cover-soils. A groundwater table of $60 \mathrm{~cm}$ below surface is certainly too high (VAN HoorN, 1958). Due to the menaces of salt and bad drainage to neighbouring lower lying soils, the water table in spring cannot be raised higher than appr. $90 \mathrm{~cm}$ below surface. Even in that case the production will be $11 \%$ too low.

Increasing the depth of the groundwater, e.g. by better drainage of neighbouring polders, can severely damage the agricultural value of clay cover-soils. If the spring groundwater table comes down from 90 to $150 \mathrm{~cm}$, one looses some $18 \%$ of the agricultural yield.

Deep-plowing gives a complete improvement of clay cover-soils when the groundwater is not deeper than $100 \mathrm{~cm}$ below surface. With deeper groundwater tables the profit of deep plowing decreases with the depth of the groundwater to less than $10 \%$.

All clay cover-soils with a clay cover of $30 \mathrm{~cm}$ can be improved by sub-irrigation during the month of March to about $100 \mathrm{~cm}$, but only if once deep-plowed to $60 \mathrm{~cm}$. In many cases it is possible to plow deeper. Then the amount of available moisture becomes larger than the figures given in TABLE 4. For instance, if the soil is plowed to $75 \mathrm{~cm}$, the moisture in the root zone increases with about $10 \mathrm{~mm}$ with deep groundwater tables. If the groundwater depth is $180 \mathrm{~cm}$, the sub-root moisture increases from 85 to $96 \mathrm{~mm}$, that is half the difference between 85 and 107. So the total amount of moisture increases with $10+11=21 \mathrm{~mm}$. 


\section{Reliability of the conclusions}

The conclusions are based upon the pF-curves and the capillary conductivity of the soil. Of course the moisture characteristics of all clay cover-soils are not the same. But the differences are not that large, that they are seriously interfering with the basic conclusions. The capillary conductivity, however, shows a large variation (see FIG. 2). Many high points in the diagram are more than one unity higher than the lowest points. Since the scale for the conductivity is logarithmic, this means that the conductivity of the high points is more than 10 times that of the low points. According to DARCY's law the moisture flow velocities vary in the same degree. In order to determine what is the importance of these differences, the data of TABLE 7 have been calculated for two other values of the constant in formula (1). Instead of formula (1) two other formulas are used, form. (1a) and (1b).

$$
\begin{aligned}
& \log \lambda=-3 \log \psi+4,75 \\
& \log \lambda=-3 \log \psi+5,15
\end{aligned}
$$

The mean error of the height in formula (1) through the points of FIG. 2 is 0,05 . So the distances of the curves (1a) and (1b) from the original line is 4 times the mean error. So there is a very high degree of certainty that the real value of the constant lies between 4,75 and 5,15. With the formula's (1a) and (1b) the whole calculation was repeated and other tables 7 were found. The results are shown in TABLE 8. The differences are much smaller than originally was expected. The data for the highest value of $b$ are of about the same order as the data with a $30 \mathrm{~cm}$ higher groundwater table for the lowest value of $b$. This means that the preliminary conclusions in terms of groundwater depth, are reliable within $30 \mathrm{~cm}$ with a very high degree of certainty.

TABLE 8. Agricultural production capacities on clay cover-soils with different values of capillary conductivity of the sand

\begin{tabular}{cccccccc}
\hline \multirow{2}{*}{$\begin{array}{c}\text { Depth of water table } \\
\text { in spring }\end{array}$} & \multicolumn{3}{c}{ Before plowing } & & \multicolumn{3}{c}{ After plowing } \\
\cline { 2 - 4 } \cline { 6 - 8 } & $\mathrm{b}=4,75$ & 4,95 & 5,15 & & $\mathrm{~b}=4,75$ & 4,95 & 5,15 \\
30 & 97 & 98 & 100 & & 100 & 100 & 100 \\
60 & 89 & 93 & 97 & & 100 & 100 & 100 \\
90 & 85 & 89 & 92 & & 98 & 99 & 100 \\
120 & 74 & 77 & 81 & & 90 & 94 & 97 \\
150 & 69 & 71 & 73 & & 79 & 82 & 86 \\
180 & 65 & 67 & 69 & & 74 & 76 & 78 \\
\hline
\end{tabular}

\section{LITERATURE}

BERG, C. VAN DEN

GARDNER, W. R.

Hidding, A. P., and

C. VAN DEN BERG
1955 Wortelproblemen in oude gronden. De Plantenwortel in de landbouw. Staatsdrukkerij. The Hague 1955, 147-155.

1958 Some steady state solutions of the unsaturated moisture flow equation with application to evaporation from a water table. Soil Sci. 85, 228-234.

1960 The relation between pore volume and the formation of root systems in soils with sandy layers. Congr. Int. Soc. Soil Sci. 1960. 
HOORN, J. W. vaN

KUIPERS, S. F.

Penman, H. L.

STAPLE, W. J., and J. J. LeHANE

WESSELING, J.

WIND, G. P.

WIT, C. T. DE
1958 Results of a groundwater level experimental field with arable crops on clay soil. Neth. J. agr. Sci. 6, 1-10.

1960 A contribution to the knowledge of the soils of SchouwenDuiveland and Tholen according to the conditions prior to 1953. Versl. Landbouwk. Onderz. 65-7.

1948 Natural evaporation from open water, bare soil and grass. Proc. Roy. Soc. No. 193, 120-145.

1954 Wheat yield and use of moisture on substations in Southern Saskatchewan. Canad. J. Agr. Sci. 34, 460-468.

1957 Enige aspecten van de waterbeheersing in landbouwgronden. Versl. Landbouwk. Onderz. 63.5.

1954 Verschillen in waterhuishouding tussen grasland en bouwland. Verslag CILO 1954, p. 126-132.

1955 A field experiment concerning capillary rise of moisture in a heavy clay soil. Neth. J. agr. Sci. 3, 60-69.

1958 Transpiration and crop yields. Versl. Landbouwk. Onderz. 64-6. 